\title{
ポリプロピレンーポリエチレン複合繊維の 潜在捲縮抑制に関する研究*
}

$$
\begin{aligned}
& \text { チッソポリプロ繊維株式会社 富 岡 亭 } \\
& \text { チッッ株 式会社 小島 男 }
\end{aligned}
$$

\section{CONTROL OF THE LATENT CRIMPABILITY IN POLYPROPYLENE/POLYETHYLENE BICOMPONENT FIBERS* ${ }^{*}$}

\author{
By Susumu Tomioka*2 and Morio Kojima ${ }^{* 3}$ \\ *2 (Chisso Polypro-Fiber Co. Ltd., 230 Kawada-cho, Moriyama, \\ Shiga, Japan) \\ *3 (Chisso Corporation, 2-7-3 Marunouchi, Chiyodaku, Tokyo, Japan)
}

A study of controlling the latent crimpability in the bicomponent polyethylene/polypropylene fibers has been made according to the information on the elastic and thermal shrinkages for each component of the fiber.

The low latent crimpability can be obtained by drawing at $100^{\circ} \mathrm{C}$ or higher and a drawing ratio of 3 or larger of the bicomponent fiber of which the flow rate ratio of the component polymers is larger than 3.

The results are explained in terms of the temperature effect which gives the different shrinkage to each of the two components, depending on the shape of the interface between them.

(Received November 21, 1979)

\section{1. 緒言}

一般に異成分から成る複合瀻䧽は，潜在撩縮性能を有 し 1 9)，低融点成分を熱によって活性化させる際に，3 次元のスパイラル状捲縮を発現し，大きな熱収縮をとも なう。このような複合紻維を不織布素材として利用する 場合には，潜在捲縮性能が䄉維集合体に大きな収縮をあ たえ好ましくない。

複合緎稑の潜在捲縮性能に関して，羊毛樣の風合，ス トレッチ性，高高性等を得る目的のために，良好な潜在 捲縮性能付与の観点加らの研究は数多くあるが ${ }^{4}$ 㧕制 という観点加らの研究は比較的少ない( ${ }^{7 \sim 8)}$ 。 前報 ${ }^{9)}$ では，ポリプロピレン(以下PPと略記)とポリ

゙この報文を「複合ポリオレフィン繊維の開発に関 する研究(第 2 報)、Studies on Bicomponent Polyolefin Fibers (Part 2)」とする。
エチレン(以下 $\mathrm{PE}$ 上格記)を複合战分とする複合䋐維の 可紡性，剥離性について考察したか，本報告では，PP， PEの分子舅ならびに延伸条件の潜在捲維性能に及ぼす 影響について検討し，その効果について考察した。

\section{2. 実験方法}

\section{1 試 料}

前報 ${ }^{9)}$ と同様，次のPPおよびPEを用いた。 PP；チッソポリプロS-5016, S-5046, S-5056 HDPE ; チッソポリエチ $\mathrm{M}-850, \mathrm{M}-880, \mathrm{M}-690$,

$$
\mathrm{M}-691, \mathrm{M}-692
$$

2.2 紡 糸 前報 ${ }^{9)}$ と同じ複合紡糸装置に紡糸口径：0.6 mm，口長 ; $6 \mathrm{~mm}$ ，ホール数；600並列型複合紡系用口金を用い て次の条件で紡系しだ。

紡系温度; 押出機先端部 $\mathrm{PP}$ 側 $300^{\circ} \mathrm{C}$ 


$$
\text { 紡年 } 265^{\circ} \mathrm{C}
$$

複合成分比; $1: 1$

吐出 量; $72 \mathrm{~g} / \mathrm{min} \times 2$

捲取速度; $300 \mathrm{~m} / \mathrm{min}$

前報 ${ }^{9}$ に報告の可紡性に問題のあるあのも検矿試料と した関係上，未延伸デニールは $72 \mathrm{~d} / \mathrm{fil}$ とした。

単独成分䄉維は上記紡系条件で片側成分の吐出を停止 した後，他方のギヤーポンプのみを回転させて得た。し たがって未延伸デニールは $36 \mathrm{~d} / \mathrm{fil}$ となる。

\section{3 延 伸}

電気加熱方式の熱ロールを有する小型延伸機を用いて, 各所定の温度书よび延伸比にて延伸した。

2.4 紡系後フローレートおよびフローレート比 前報 ${ }^{9)}$ と同様にして測定した。

以下本文中においてもFRと記述した場合は，紡系後 フローレートを意味し，FR比は，PEのPPに対するFR の比を意味する。

\section{5 単独成分驖維の弾性収縮ならびに熟収縮の 測定}

\subsection{1 弾性収縮}

島津オートグラフ(IM-100 形)を用い試長 $10 \mathrm{~cm}$ (室 温延伸の場合)扰よび $5 \mathrm{~cm}\left(100^{\circ} \mathrm{C}\right.$ 延伸の場合)，引張り 速度 $100 \% / \mathrm{min}$ で，延伸比 $2 ， 3 ， 4 ， 5$ 倍飞延伸し，1 分間所定の延伸比保持した後応力を除去して得られる 図1に示したような応力ーひずみ曲線拈よびその回復曲 線より $\overline{B A} / \overline{O A} \times 100(\%) を$ 求め，てれを弾性収縮率上 した。

\subsection{2 熱収縮}

弾性収縮測定後の試料を熱收縮測定試料とした。試料 にデニールの $1 / 30$ グラムの初荷重をかけ、試料長 $\left(l_{0}\right)$ をはかった後， $120 \pm 1^{\circ} \mathrm{C}$ 恒温乾燥器中で 30 分間無荷 重, 無緊張状態で熱処理して, 室温冷却後再び初荷重を

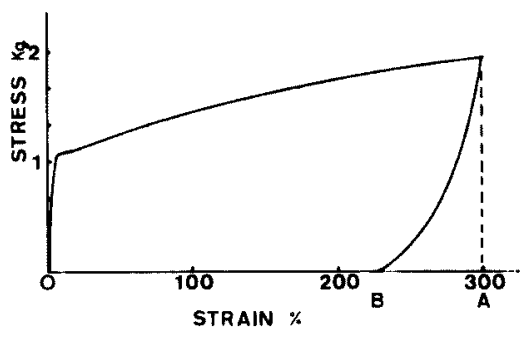

Fig, 1. Stress-Strain and Recovery Curve for the PP (S-5016).

Fiber denier; 2.160

Drawing temperature; Room temperature Drawing ratio; 4
加け，熱処理後の試料長(りをはかり，次式により熱収 縮率を求めた。

熱收縮率 $(\%)=l_{0}-l / l_{0} \times 100$

\section{6 不織布熱収縮}

$18 \mathrm{~d} \times 64 \mathrm{~mm}$ の複合緇維をフラットカートに供給しカ ードウェッブをドラムに積層した後， $25 \mathrm{~cm} \times 25 \mathrm{~cm}$ (目 付 12〜13 g) に切断し，これを両面クラフト紙にてはさ み, $145 \pm 1^{\circ} \mathrm{C}$ ○恒温乾燥器中で 30 分間無荷重, 無緊張

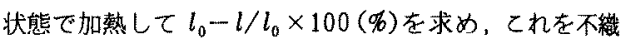
布熱収縮率とした。

但し， $l_{0}$ は熱処理前の試料長 $(25 \mathrm{~cm})$ $l$ は熱処理後の繊維配列方向の試料長

\section{3. 実験結果と考察}

\section{1 複合成分の分子量ならびに延伸条件の替在 撩縮性能におよぼす効果}

表1に分子量の異なるPPおよびPEの組合せによっ て得られた複合繼維の不織布熱收縮率を示す。

図 2 にPP成分 S-5016 上分子量の異なるPEを組合 女大場合, 図 $3 k \mathrm{PE}$ 成分M-691 と分子量の異なる $\mathrm{PP}$ を組合せた場合のFR比上不織布熱収綰率の関䋆を示す。 $F R$ 比 1 付近での不織布熱收綰率は，複合繊維の潜在捲 縮の発現化基因して極如て高く，FR比の上昇上共汇急 激に低下しFR比 3.5 以上では殆ど 0 亿近つく。とのと とはPPのFRが低く，PEのFRの高い複合成分の組合

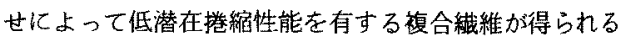
ことを示している。

一方，表1亿示高試料A-1，A-2，A-3、A-4 亿つ いては，延伸温度を変え，また $\mathrm{A}-3$ については延伸比 を変えて延伸を行った場合には，そ机でれ图4および図 5 に示すような不織布熱収縮率との関係加得られる。乙 の結果延伸条件として延伸温度 $100^{\circ} \mathrm{C}$ 以上，延伸比 3 以 上とした場合に，低潜在捲縮性能の複合䄳維の得られる ことがわかる。

複合瀻維の捲縮に関しては，延伸後弛楥された際の複

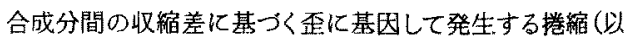
下顕在捲縮と称する）之他緩状態で熱処理を受けた際の 両成分の熱收縮差に上って生じる歪のため汇発生する棬 縮 (潜在捲縮) とがある。

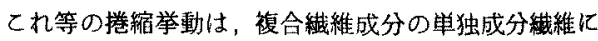
ついての応力ーひずみ曲線およびその回復曲線から弾性 収縮を求め ${ }^{12)}$ ，さらに熱收縮を求めて取り扱う事が出来 る。

\subsection{1 单独成分緉維の収縮挙動}

$\mathrm{PP}: \mathrm{S}-5016$ と $\mathrm{PE}: \mathrm{M}-691$ さらに比較のために, PP : S- 5048 について室温拈よび $100^{\circ} \mathrm{C}$ で延伸した場 
Table 1. Description of polymers and characteristics of PE/PP bicomponent fibers.

\begin{tabular}{|c|c|c|c|c|c|c|c|}
\hline \multirow[b]{2}{*}{$\begin{array}{c}\text { Sample } \\
\text { No. }\end{array}$} & \multicolumn{2}{|r|}{ PP } & \multicolumn{2}{|r|}{$\mathrm{PE}$} & \multirow{2}{*}{$\begin{array}{l}\text { FR after } \\
\text { Spinning } \\
\text { (P.E/P. P) }\end{array}$} & \multirow[b]{2}{*}{$\begin{array}{c}\text { FR } \\
\text { Ratio }\end{array}$} & \multirow{2}{*}{$\begin{array}{l}\text { Heat shrinkage } \\
\text { of the non-woven } \\
(\%)\end{array}$} \\
\hline & Grade & $\begin{array}{l}\text { M. W. after } \\
\text { Spinning }\end{array}$ & Grade & $\begin{array}{l}\text { M. W.*after } \\
\text { Spinning }\end{array}$ & & & \\
\hline $\begin{array}{l}A-1 \\
A-2 \\
A-3 \\
A-4 \\
\end{array}$ & $S-5016$ & $2.5 \times 10^{5}$ & $\begin{array}{l}M-680 \\
M-690 \\
M-691 \\
M-692\end{array}$ & $\begin{array}{l}3.8 \times 10^{4} \\
3.3 \times 10^{4} \\
3.0 \times 10^{4} \\
2.7 \times 10^{4} \\
\end{array}$ & $\begin{array}{l}12.1 / 11.3 \\
23.1 / 9.8 \\
33.6 / 10.6 \\
50.2 / 10.0 \\
\end{array}$ & $\begin{array}{l}1.1 \\
2.4 \\
3.2 \\
5.0\end{array}$ & $\begin{array}{r}37 \\
15 \\
2 \\
0\end{array}$ \\
\hline $\begin{array}{l}\mathrm{B}-1 \\
\mathrm{~B}-3\end{array}$ & $S-5048$ & $2.1 \times 10^{5}$ & $\begin{array}{l}M-680 \\
M-691\end{array}$ & $\begin{array}{l}3.8 \times 10^{4} \\
3.0 \times 10^{4}\end{array}$ & $\begin{array}{l}14.5 / 18.5 \\
33.9 / 17.4\end{array}$ & $\begin{array}{l}0.8 \\
2.0\end{array}$ & $\begin{array}{l}45 \\
18\end{array}$ \\
\hline $\begin{array}{l}\mathrm{C}-1 \\
\mathrm{C}-3\end{array}$ & $S-5056$ & $1.8 \times 10^{5}$ & \begin{tabular}{|l|}
$M-680$ \\
$M-691$ \\
\end{tabular} & $\begin{array}{l}3.8 \times 10^{4} \\
3.0 \times 10^{4}\end{array}$ & $\begin{array}{l}14.4 / 30.0 \\
31.3 / 32.3 \\
\end{array}$ & $\begin{array}{l}0.5 \\
1.0 \\
\end{array}$ & $\overline{46}$ \\
\hline $\mathrm{D}$ & $S-5016$ & $2.5 \times 10^{6}$ & - & - & $-/ 10.7$ & - & 5 \\
\hline
\end{tabular}

Drawing condition; Drawing temperature $100^{\circ} \mathrm{C}$

Fiber denier ; 18 denier Drawing ratio 4.0

M.W. ; molecular weights calculated from following equation.

$[\eta]=0.80 \times 10^{-4} \bar{M}^{0.80}\left(\text { Tetralin } 135^{\circ} \mathrm{C} \text { for } P P\right)^{10)}$

$[\eta]=3.78 \times 10^{-4} \bar{M}^{0.72}\left(\text { Tetralin } 130^{\circ} \mathrm{C} \text { for } \mathrm{PE}\right)^{11)}$

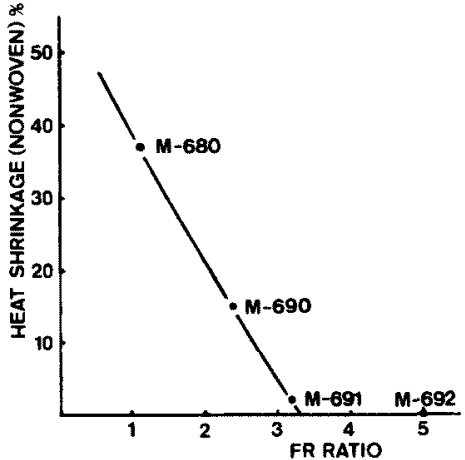

Fig. 2. Heat shrinkage of nonwoven vs. flow rate ratio for HDPE/PP (S-5016) bicomponent fibers.

Drawing temperature; $100^{\circ} \mathrm{C}$

Drawing ratio; 4

合の延伸比と弾性取縮率，熱収縮率之の関係図 6 因

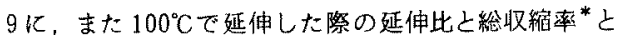
の関係を図 10 に示した。

弾性収縮ならびに熱収縮は，図 6〜7および図 8〜9に 示されるように、試料の分子量，延伸条件によって変る。 延伸温度は高い程弾性収縮率ならびに熱収縮率は低下す る。又，延伸比との関係においては，弾性取縮は延伸比 との関保においては，弾性収繀は延伸比の增大上其に低 下するが熱収䆶は延伸比 3 付近に最大値を有する。

\section{1 .2 複合繊維の捲縮挙動}

*釉収縮率 $(\%)=(E+H-E H) \times 100$

$E$ : 弾性収縮率 $(\%) / 100 ， H$ : 熱収縮率 $(\mathscr{\%}) / 100$

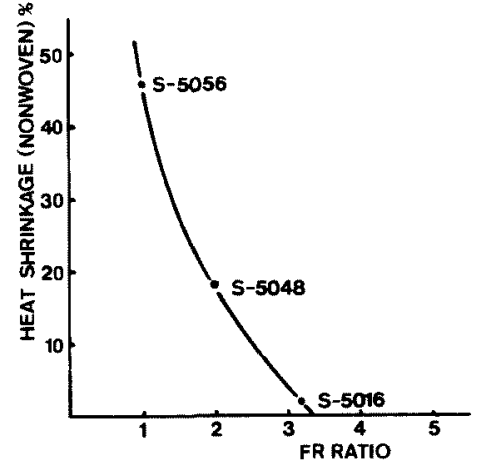

Fig. 3. Heat shrinkage of nonwoven vs. flow rate ratio for $\mathrm{PE}(\mathrm{M}-691) / \mathrm{PP}$ bicomponent fibers.

Drawing temperature; $100^{\circ} \mathrm{C}$

Drawing ratio; 4

因6〜9には，S-5016，S-5048，M-691の収縮挙 動を示すにとどまっているが，延伸温度 $\left(100^{\circ} \mathrm{C}\right)$ 延伸比 (4.0 倍)の高い所で分子量と単系の収縮率において，

PP $\quad \mathrm{S}-5016>\mathrm{S}-5048>\mathrm{S}-5016$

PE $\quad \mathrm{M}-680>\mathrm{M}-690>\mathrm{M}-691>\mathrm{M}-692$

の関係にあり，分子量の低い程(FRの高い程)弾性収縮， 熱収縮其に低下する。

低潜在捲縮性能の $\mathrm{PE} / \mathrm{PP}$ 複合䋐維は，PP, PE成分 間の熟収縮差を小さくすることによって得られる。2成 分間の熱収縮差は（3.1.1）に述へたように単独成分䋐維 の取縮挙動の検討加ら，分子量の小さいPEと分子量の 大きいPPを組合せて得られる複合㵶維を高温，高倍率 


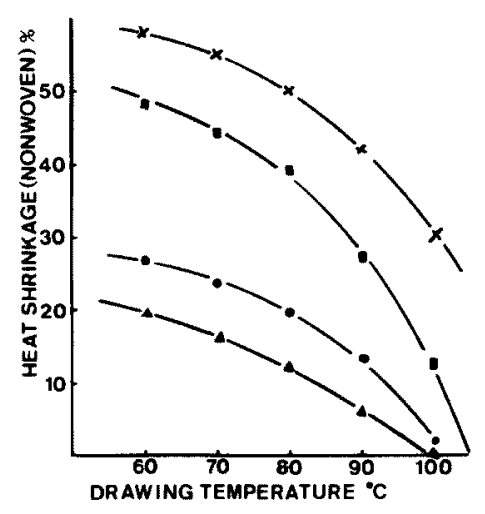

Fig. 4. Heat shrinkage of nonwoven vs. drawing temperature for PE/PP (S-5016) bicomponent fibers.

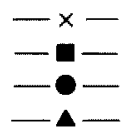

PE (M-680)/PP (S-5016)

PE (M-690)/PP (S-5016)

PE (M-691)/PP (S-5016)

$\mathrm{PE}(\mathrm{M}-692) / \mathrm{PP}(\mathrm{S}-5016)$

Drawing ratio; 4

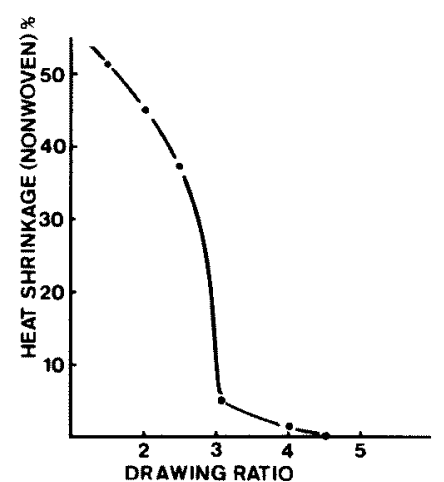

Fig. 5. Heat shrinkage of nonwoven vs. drawing ratio for the $\mathrm{PE}(\mathrm{M}-691) / \mathrm{PP}$ (S-5016) bicomponent fiber.

Drawing temperature; $100^{\circ} \mathrm{C}$

で延伸を行うことによって，小さくなる㑯向にあること が加った。

しかしながら複合繊維のすへてて捲縮挙動は，単独成 分緎維に関して検討した結果で説明するてとは出来ない。 例えば図 7 に示した逐伸比之弾性収縮との関係において 延伸比 5 の場合の PP (S-5016) と PE (M-691) 上の弾 性収縮差は、ほとんどないととが観測されていることか ら，てれらの組合せによる複合絿維の㩆在捲縮は小さい と考えられるし，また図9にみられるように延伸比を5 とした場合のPE (M-691)の熱収縮は PP (S-5016)の

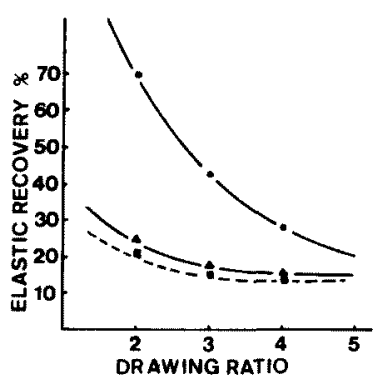

Fig. 6 Elastic recovery vs. drawing ratio for $\mathrm{PP}$ and PE fibers.

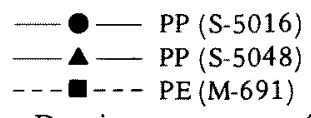

Drawing temperature; $20^{\circ} \mathrm{C}$

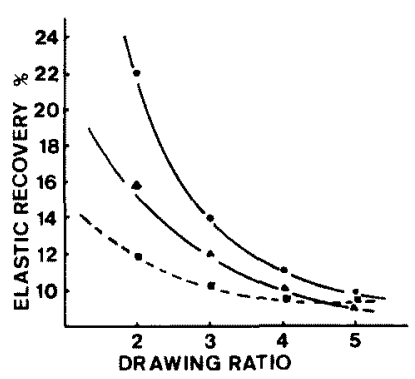

Fig. 7. Elastic recovery vs. drawing ratio for $\mathrm{PP}$ and PE fibers.

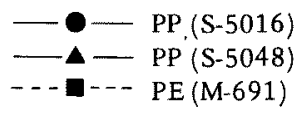

Drawing temperature; $100^{\circ} \mathrm{C}$

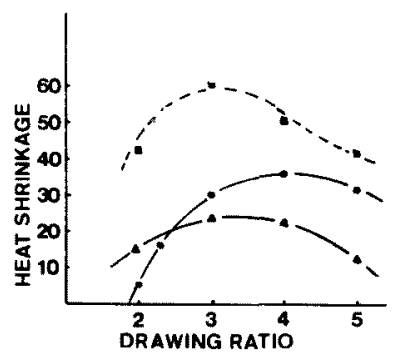

Fig. 8. Heat shrinkage vs. drawing ratio for $P P$ and PE fibers.

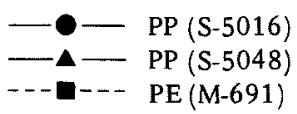

Drawing temperature; $20^{\circ} \mathrm{C}$ 


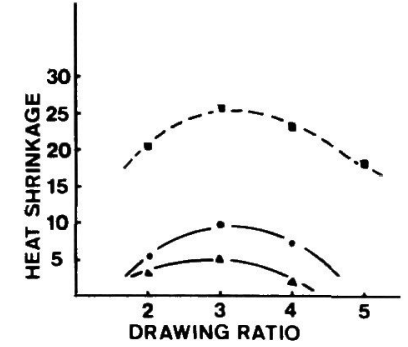

Fig. 9. Heat shrinkage vs. drawing ratio for $P P$ and PE fibers.

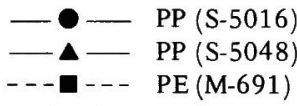

Drawing temperature; $100^{\circ} \mathrm{C}$

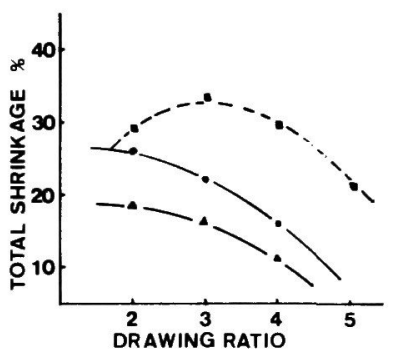

Fig. 10. Total shrinkage vs. drawing ratio for $\mathrm{PP}$ and PE fibers.

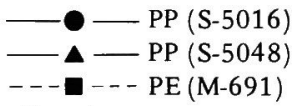

Drawing temperature; $100^{\circ} \mathrm{C}$

それより大きく，熱処理後は，PE成分を内側とする潜 在捲縮の発見が予想される。しかし実際には，乙の場合 図11(a)に示したように 13 山 $/ 10 \mathrm{~cm}$ の大きな顕在捲縮 がみられる。この際の捲縮は図 12 に示した通りPP成 分が内側に配位し，弾性収縮率が PE成分のそれよりあ

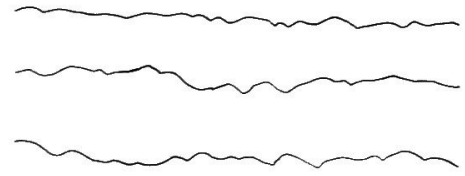

(a)

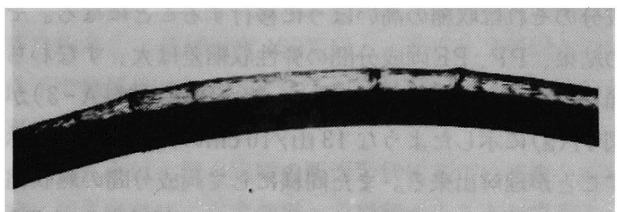

Fig. 12. Longitudinal view of the PE (M-691)/ PP (S-5016) bicomponent fiber showing PP side taking the inside track of the crimp bend.

大きいことを示している。一方熱処理後では図11(b)に みられるように捲縮は減少し 9 山 $/ 10 \mathrm{~cm}$ となる。

このように単独成分繊維の収縮挙動から推察した複合 繊維の捲縮挙動は，各成分の流動特性に由来して発現す る繊維の断面形状に関係するために，功らずしも実際 の場合と一致しない。図 13 亿試料 A-3 [PE (M-691)/ $\mathrm{PP}(\mathrm{S}-5016)]$ の断面形状を示す。乙の場合, 内心を形 成する PP成分の熱延伸による収縮低下の効果はPP 単独成分の場合に比べて小さいが，PP成分を取り巻 く $\mathrm{PE}$ 成分に対する同様の効果は，その単独成分の場合 とほほ同じであると考えられる。したがって図 7 お び図 9 に示されるPE成分の収縮曲線は変らないが, PP

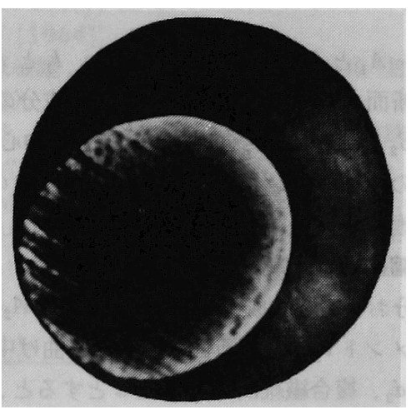

Fig. 13. Interface shape of the PE (M-691)/ PP (S-5016) bicomponent fiber.

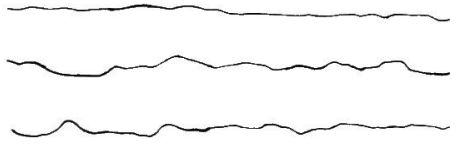

(b)

Fig. 11. Numbers of apparent (after drawing) and latent (after heat treatment) crimp of the PE (M-691)/PP (S-5016) bicomponent fiber.

Drawing temperature; $100{ }^{\circ} \mathrm{C}$

Drawing ratio; 5
(a) ; Apparent crimp
(b) ; Latent crimp 
成分のそれは收縮の高いはうに移行することになる。そ の結果，PP，PE両成分間の弾性取縮差は大，すなわち 顕在捲縮が発現することになり，複合緎維(試料 $\mathrm{A}-3$ )が 困11（a）に示したような 13 山/10 cmの大きな捲縮を示 すととが理解出来る。また同様にして両成分闃の熱収縮 差は小，すなわち潜在捲縮は抑制され，熱処理後はPE 成分の収縮はPP成分のそれより大きくなるために今ま でPP成分を内側としていた捲縮は反転し，捲縮数は， 図11(b)にみら机るように 9 山 $/ 10 \mathrm{~cm}$ に減少する。

\section{2 複合繶維の断面形状が潜在捲縮性能に及ほ す効果}

\subsection{1 捲縮繊維の曲率}

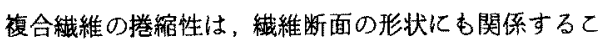
とが知られており ${ }^{12}$ 撩繀性に関して一般的理諭式も導出

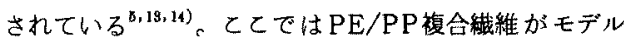
的に図 14 (a) 扰よび図 14 (b)の断面形状をむった場合の 捴縮織維の曲率 $K_{\mathrm{a}}$ および $K_{\mathrm{b}}$ を Jimoshenkoの理論に基 ついて導加れた

$K_{0}=1 / p_{0}$

$$
=\frac{\Delta L / L}{\left(d_{1}+d_{2}\right)+\frac{1}{d_{1}+d_{2}}\left[I_{1}\left(\frac{1}{A_{1}}+\frac{n}{A_{2}}\right)+I_{2}\left(\frac{1}{A_{2}}+\frac{1}{n A_{1}}\right)\right]}
$$

ここに， $A_{1}$ と $A_{2}$ は 2 成分の断面積， $I_{1}$ と $I_{2}$ はこれに 対店する断面の慣性モーメント，nは両成分のヤング率 の比 $E_{1} / E_{2} ， d_{1}$ 之 $d_{2}$ は，各成分の断面の中心から曲げ 中立線迄の距稚， $\Delta L / L$ は両成分の長さ変化の差， $K_{0}$ は捲縮繊維の曲率， $\rho_{0}$ は，その曲率半径をあらわす。

\section{(1) 港韄棈維の曲率 $\left(K_{\mathrm{a}}\right)$}

$\mathrm{PE}$ 成分および $\mathrm{PP}$ 成分の断面積を $A_{1} ， A_{2}$ ，断面の 慣性モーメント $I_{1} ， I_{2}$ ，断面の重心加ら曲げ中立線迄の 距離 $d_{1}, d_{2}$, 複合瀻維断面の半径 $a$ とすると，

$$
A_{1}=A_{2}=\pi a^{2} / 2
$$

図14のような質点 $(m)$ の連続的な集合体では重心 $y_{\mathrm{G}}$ は、

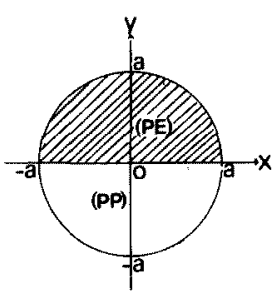

(a)

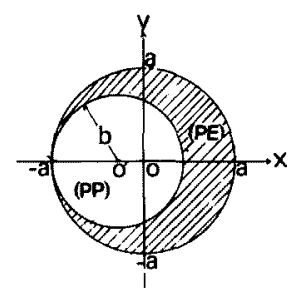

(b)
Fig. 14. Schematic representation for interface shapes of PE/PP bicomponent fibers.

(a); Side-by-side type

(b); Eccentric sheath-core type.
$y_{\mathrm{G}}=\int x d m / \int d m$ で求められるから.

$$
\begin{aligned}
d_{1} & =d_{2}=\frac{\int_{-a}^{a} y \sqrt{a^{2}-y^{2}} d y}{\pi a^{2} / 2} \\
& =4 a / 3 \pi
\end{aligned}
$$

$\mathrm{PE}$ 成分扰よびPP成分の $x$ 軸方向の慣性モーメント， $I_{1 x} ， I_{2 x}, y$ 軸方向の慣性モーメント． $I_{1 y} ， I_{2 y}$ とする \llcorner

$$
\begin{aligned}
I_{X}=I_{1 x}=I_{2 x} & =\int_{-a}^{a} x^{2} d m \\
& =\int_{-a}^{a} x^{2} \sqrt{a^{2}-y^{2}} d x \\
& =\frac{a^{4} \pi}{8} \\
I_{Y}=I_{1 y}=I_{2 y} & =2 \int_{0}^{a} y^{2} \sqrt{a^{2}-y^{2}} d y \\
& =\frac{a^{4} \pi}{8} \\
I_{1}=I_{2}=I_{X}+I_{Y} & =\frac{a^{4} \pi}{4}
\end{aligned}
$$

両成分のヤング率比，nは捲縮曲率に対して無視出来る 程度の効果であることが知られており ${ }^{14)}, n=E_{1} / E_{2} \div 1$ と兒るととがでる。

$\Delta L / L=C$ (const)として (2)，(3)，(4)を(1)式に代入 して捲縮曲率 $K_{\mathrm{a}}$ を求める。

$$
K_{\mathrm{a}}=\frac{12 \cdot \pi \cdot C}{\left(32+9 \pi^{2}\right) a}
$$

\section{(2) 捲狳栈維の曲率 $\left(K_{\mathrm{b}}\right)$}

因 14 (b)に施いて，内接するPP成分の断面半径 $b$ と $し A ， I ， d ， \Delta L / L$ に関して(3.2.1(1))之同様の記号を 用いる。

$$
\begin{aligned}
A_{1}= & A_{2}=\frac{\pi a^{2}}{2}=\pi b^{2} \\
d_{1}= & d_{2}=(\sqrt{2}-1) b \\
I_{1 x}= & 2 \int_{-a}^{a} x^{2}\left(\sqrt{a^{2}-x^{2}}-\sqrt{\left.b^{2}-\{x+(\sqrt{2}-1) b\}^{2}\right) d x}\right. \\
= & \frac{8 \sqrt{2}-9}{4} b^{4} \pi \\
I_{1 y}= & 2 \int_{-a}^{a} y^{2} \sqrt{a^{2}-y^{2}} d y \\
& -2 \int_{-b}^{b} y^{2}\left\{\sqrt{a^{2}-y^{2}}-(\sqrt{2}-1) b\right\} d y \\
= & \frac{3 b^{4} \pi}{4}+\frac{4(\sqrt{2}-1)}{3} b^{4}
\end{aligned}
$$

$$
\begin{aligned}
& I_{1}=I_{1 x}+I_{1 y}=\frac{4 \sqrt{2}-3}{2} b^{4} \pi+\frac{4}{3}(\sqrt{2}-1) b^{4} \text { (8) } \\
& I_{2}=I_{2 x}+I_{2 y}=\frac{b^{4} \pi}{4}
\end{aligned}
$$

(6)，(7)，(8)，(9)を(1)式に代入して捲縮曲率 $K_{\mathrm{b}}$ を 
求める。

$$
K_{\mathrm{b}}=\frac{12 \sqrt{2} \pi \cdot C}{a\{(33 \sqrt{2}+9) \pi+16)\}}
$$

\subsection{2 棬縮性能の比較}

捲縮数 $\left(C_{f}\right)$ は䄉維実長 $\left(L_{0}\right)$ 当りの撩縮ループ数 $\left(C_{\mathrm{n}}\right)$ と して定義され捲縮曲率 $\left(K_{0}\right)$ 亿直接関係している ${ }^{14)}$ 。

$$
C_{\mathrm{f}}=C_{\mathrm{n}} / L_{0}=1 / 2 \pi \rho_{0}=K_{0} / 2 \pi
$$

図 14 (a) 拉よび図 14(b)の断面を有する複合瀻維が $\Delta L / L$ の長さ変化した時に発現する捲縮数を $C_{\mathrm{t} 1}$ および C

$$
\begin{aligned}
& C_{\mathrm{f1}}=K_{\mathrm{a}} / 2 \pi=\frac{6 C}{\left(32+9 \pi^{2}\right) a} \div 0.049 \mathrm{C} / a \\
& C_{f 2}=K_{\mathrm{b}} / 2 \pi=\frac{6 \sqrt{2} C}{\{(33 \sqrt{2}+9) \pi+16\} a} \div 0.044 C / a \\
& \text { (11)，(12)より } C_{\mathrm{f} 1}>C_{\mathrm{f} 2} \\
& \frac{C_{f_{1}}-C_{f 2}}{C_{f 1}} \times 100 \div 10.2 \text { (क) }
\end{aligned}
$$

图 14 (b)のような断面形状(偏心 Sheath-Core 型)を 有する複合瀻䧽は，Side-by-side 型(図 14 (a)) 比比し て撩縮しにくいととが，立証されたが，捲縮数の比でみる と $10 \%$ 程度劣るとすぎい。

したがってPE/PP複合䋐維の試料A-3 が図 13 の様 な断面形状をとることによる材料力学面加らの潜在捲縮 能抑制効果は，棬縮数にして高々 $10 \%$ 程度であり，支配 的要因とはいえない。

\section{4. 結論}

$\mathrm{PE}, \mathrm{PP}$ を複合成分とする複合型接着用䋊維の潜在撩 缩能の㧕制について検討を行った。
その結果，FR比が 3 以上となるよう両成分を組合せ 複合紡系し，延伸温度 $100^{\circ} \mathrm{C}$ 以上，延伸比 3 倍以上の条 件下で熱延伸することによって，潜在捲縮性能の抑制か 可能となるととを見出した。

このととは，複合䋐維の断面形状に基ついて複合成分 間に起る延伸時の温度効果から説明することができる。

\section{文献}

1) Sisson (Avisco), U.S.P. 2,439,815-1948

2) H. F. Mark, S. M. Atlas, E. Cernia, "Man-made Fibers" Interscience Publishers, U.S.A., p 391 (1967)

3) S. Davis, C.R. Sissons (British Nylon Spinners), U.S.P. 3,595,731-1971

4) T. D. Brawn, W. J. Onion, J. Text Inst., 52, T101 (1961)

5) R. H. Brand, S. Baker, Tex. Res. J., 32, 39 (1962)

6) R. Jeffries, "Bicomponent Fibers" Merrow Publishing Co. Ltd., Great Britain p 29 (1971)

7) W. Kranz (E.I. du Pont), U.S.P. 3,589,9561971

8）松井雅男，山召正博(鐘紡)；特公昭 46-5247

9) 富岡 享, 小島盛男; 緎学誌, $35 ， 68$ (1979)

10) P. Parrini, Makromol. Chem., 38, 27 (1960)

11) C. T. Stacy, R. L. Arnett, J. Polym. Sci., A-2, $167(1964)$

12) 吉原敏雄;「瀻維の形成之構造の発現 (III)」(織維学 会編)，化学同人, p.75(1971)

13) 安田 浩, 長野和義, 松尾達樹; 緎学誌, 27, 168 (1971)

14) E. M. Hicko, E. A. Tippetts, J. V. Hewett, R. H. Brand, "Man-made Fibers" (H. F. Mark, S. M. Atlas, E. Cernia) Interscience Publishers. U.S.A. p 399 (1967) 